\title{
Wittgenstein e Walter Benjamin: INQUIETAÇÕES ÉTICAS E FILOSÓFICAS COMO \\ FORMAS DE VIVER E PENSAR
}

\author{
Elaine Deccache Porto e Albuquerque* \\ Solange Jobim e Souza**
}

\section{RESUMO}

$\mathrm{O}$ artigo analisa a filosofia da linguagem e a ética em Wittgenstein e Walter Benjamin, tendo como propósito tornar consistentes as concepções teóricas que se aproximam, sem deixar, contudo, de enfatizar a especificidade inerente aos percursos do pensamento de cada um e os seus nítidos distanciamentos. Destaca-se o entendimento que ambos oferecem sobre as possibilidades de expandir os limites da linguagem como uma questão filosófica fundamental, apontando as conseqüências desta tentativa nas formas de viver e pensar.

Palavras-chave: Wittgenstein; Walter Benjamin; ética; linguagem; conhecimento

\section{AbSTRaCt}

WitTGENSTEIN AND WaLter Benjamin: ETHICAL AND PHILOSOPHICAL CONSIDERATIONS AS WAYS OF LIVING AND THINKING

The article analyses the philosophy of language and ethics in Wittgenstein and Walter Benjamin, and its goal is to make consistent the theoretical conceptions that approach each other emphasizing, however, the specificity inherent to the course of thought of each one of them and their clear differences. The understanding that both offer about the possibilities of expanding

* Doutora em Psicologia Clínica pela Pontifícia Universidade Católica do Rio de Janeiro (PUCRio) e Orientadora Educacional do Colégio Teresiano.

** Doutora em Educação pela Pontifícia Universidade Católica do Rio de Janeiro (PUC-Rio); Professora Associada do Departamento de Psicologia da PUC-Rio; Professora Adjunta da Faculdade de Educação da Universidade Estadual do Rio de Janeiro (UERJ); Pesquisadora do CNPq. Apoio FAPERJ. 
the limits of language as a fundamental philosophical matter is highlighted, pointing out the consequences of this effort in the ways of living and thinking.

Keywords: Wittgenstein; Walter Benjamin; ethics; language; knowledge

Em memória a Anamaria Ribeiro Coutinho

I am showing my pupils details of an immense landscape which they cannot possibly know their way around. (Wittgenstein, [1929-1951] 1984: 56)

Nos domínios de que tratamos aqui, o conhecimento existe apenas como lampejos. O texto é o trovão que segue ressoando por muito tempo. (Benjamin, [1927-1940] 2006: 499)

\section{INTRODUÇÃO}

Ao ler Walter Benjamin e Wittgenstein e buscar desenvolver um diálogo entre as concepçôes de linguagem e ética destes autores, nos deparamos com um denso desafio teórico. De um lado, há o reconhecimento do enorme alcance e da capacidade intelectual e crítica de ambos para manifestar suas crenças na grandeza da experiência humana. De outro, algo que poderíamos chamar de uma grande inquietação que acompanha a compreensão de uma concepção de linguagem, a qual estaria intimamente ligada à possibilidade de tradução desta compreensão como uma experiência singular do sujeito no mundo. Aceitar este desafio e procurar ampliar o entendimento em relação aos conceitos tidos como chaves do pensamento destes autores é o propósito deste texto. Neste caso, todo o esforço se dará para tornar consistente a tentativa de transitar em meio às concepçôes de linguagem e ética que ambos oferecem, apresentando as possíveis aproximações e claros distanciamentos, mantendo com isto a especificidade inerente aos percursos do pensamento de cada um dos autores.

A filosofia de Wittgenstein elegeu a linguagem para analisar a sua capacidade de descrever o mundo de maneira adequada. Dentro dessa perspectiva, na primeira fase de sua reflexão filosófica, Wittgenstein acreditava que a lógica era a linguagem ideal para solucionar, de vez, os problemas epistemológicos da filosofia. Ainda assim, o filósofo, mesmo nesse momento, partidário de uma racionalidade altamente restritiva, percebia que a linguagem da lógica não alcançava os grandes temas humanos, ou seja, esses permaneciam fora da possibilidade de qual- 
quer análise. Por esse tempo, Wittgenstein apresentou-se como um pensador quase místico que, para propor a ética como um dos grandes temas humanos, trouxe para sua reflexão o campo da transcendência, o "fora do mundo".

$\mathrm{Na}$ segunda fase do pensamento de Wittgenstein, a lógica perde a sua primazia e passa a ser considerada como uma entre outras formas de linguagem. $\mathrm{O}$ interesse do filósofo se volta para a imensa variedade de formas que a linguagem possui, na medida em que passa a analisá-la em seus vários contextos de uso no fluxo da vida. Sob esse aspecto, o discurso sobre a ética seria, também, um, entre outros, dotado de uma intenção específica. No entanto, Wittgenstein se cala em relação a esse tema, o que, no contexto de seu pensamento, possui profundas implicaçōes.

Quanto a Benjamin, não encontramos uma teoria argumentada e didática sobre a linguagem. Sua reflexão recorre à teologia e à mística judaica para se interrogar sobre a sua essência. Assim, a teoria da linguagem em Benjamin não faz coro às preocupações científicas que, a partir do século XX, trouxeram a lingüística e as teorias semióticas para o centro da investigação e deixaram de lado, por seu caráter metafísico, a reflexão sobre a natureza da linguagem. Afastando-se de uma perspectiva instrumentalista, o filósofo pensou sobre a linguagem fora da sua dimensão comunicativa porque considerava que isso traía o objetivo do seu questionamento, qual seja, a compreensão da sua natureza mais profunda. Benjamin encontra na reflexão sobre a linguagem a possibilidade de ampliar o conceito de experiência, que a visão predominante do seu tempo reduzia ao âmbito restrito do conhecimento científico. Ao investigar a natureza da linguagem, o filósofo busca a saída para os impasses reducionistas dessa concepção restritiva de racionalidade, própria da filosofia moderna.

Benjamin constrói imagens, faz analogias e recorre, freqüentemente, a inúmeras metáforas que mostram a forma do seu pensamento. Desse modo, compondo novos critérios de exatidão, recupera a linguagem como compromisso e responsabilidade para re-significar eticamente o sujeito e a história.

\section{A PRIMEIRA FILOSOFIA DE WitTGENSTEIN}

A filosofia analítica ${ }^{1}$ faz uma distinção clara entre a primeira e a segunda fase do pensamento de Wittgenstein, sendo que a segunda surge nos escritos posteriores a 1929.

Inicialmente, Wittgenstein dedicou-se a estudar a matemática e a lógica, num tempo em que a filosofia concebia este estudo como o das relaçóes de uma linguagem independente entre entidades abstratas (platonismo) ou o estudo das 
leis do pensamento (psicologismo) ${ }^{2}$. Para ele, no entanto, estudar a lógica era investigar as formas fundamentais de qualquer sistema de representação simbólico. Assim, diferentemente dos filósofos que o antecederam, pensava que a ordenação da linguagem ordinária era completamente lógica. Desse modo, então, a análise lógica não criaria ordem onde, previamente, não existia uma ordenação, ela põe manifesto o que já existia, ainda que oculto na complexidade da linguagem ordinária (Teófilo Urdánoz, 1984). Sua investigação em direção a uma notação ideal não era considerada um progresso em relação a qualquer linguagem natural, mas buscava trazer à luz o que estava escondido em seu simbolismo.

Ainda que Wittgenstein considerasse a lógica como uma linguagem ideal, entendia que a investigação em direção à essência de uma proposição revelaria a natureza e os limites da linguagem, os limites de todos os mundos possíveis e os limites do pensamento, já que pensamento também é representação. Na lógica das proposiçôes se expressaria a lógica da linguagem, assim como toda a lógica do pensamento. Na verdade, o pensamento, as proposiçōes e a linguagem se fundem em uma só imagem dos fatos, que seria a figura lógica da realidade. A filosofia teria como tarefa, portanto, analisar a linguagem para que se revelasse a sua verdadeira forma e, assim, a relação desta com os fatos. Desse modo, então, para o filósofo, os problemas surgiam de uma má compreensão da linguagem pelo desconhecimento de sua forma lógica autêntica e da maneira pela qual esta se relaciona com o real.

Para Wittgenstein, a essência da representação estaria na descrição, na representação de um estado de coisas por meio de uma proposição ${ }^{3}$. Na medida em que nós descrevemos como as coisas são na realidade por meio de proposições (concebidas como sentenças com significado), a proposição mais simples deve conter as características essenciais requeridas para a descrição. Assim, por meio da investigação da essência de uma proposição elementar, se conseguirá a essência de toda descrição que, por sua vez, se apropriará da essência do mundo.

Toda esta reflexão foi feita pelo primeiro Wittgenstein. Fala-se em primeiro e segundo porque ele, em sua segunda fase, transfere seu interesse para a linguagem ordinária. Ao se dedicar a analisá-la, Wittgenstein percebe que a multiplicidade de significados de seus termos é derivada de seu uso e isso faz com que se oponha à antiga doutrina de uma linguagem ideal, logicamente perfeita. O filósofo critica, assim, sua postura anterior, dizendo que ela era uma ilusão nascida daquela lógica da proposição como algo único e extraordinário que se queria purificar para que refletisse, fielmente, o pensamento e os fatos. Desse modo, em sua primeira fase, em sua obra, o Tractatus logico-philosophicus, Wittgenstein ([1921] 1993) procurava examinar a linguagem para além de sua aparência, em direção à sua estrutura latente, revelando, assim, sua lógica subjacente. Tal investigação o guiaria na dire- 
ção de uma notação ideal da linguagem. Porém, em sua última fase, ele rejeitou a idéia de formular uma notação ideal e passou a concentrar-se numa cuidadosa discussão sobre o uso ordinário da linguagem.

Com esta nova concepção de linguagem, Wittgenstein elimina, de uma vez, toda uma ordem de conhecimento essencial, superior à da linguagem cotidiana em seus variados usos. O pensamento é igualmente visto como inseparável da linguagem e, portanto, neste segundo momento de suas investigações filosóficas, a análise da linguagem fica circunscrita à análise de sua função no viver cotidiano. Não há, assim, uma forma lógica a priori, nem uma linguagem ideal; só uma multiplicidade de linguagens, cada uma com sua própria lógica e que não têm nada em comum entre si; ou seja, nem se unem numa linguagem superior da qual dependem, nem apontam para uma realidade que se oculta por trás delas. Assim, Wittgenstein, com sua nova filosofia, rompe com seu pensamento anterior e com todo o pensamento tradicional relativo à teoria representacional da linguagem. A revisão filosófica feita por ele, tendo a linguagem como eixo, reordenou o entendimento sobre a produção do conhecimento, ao constatar a impossibilidade do acesso a uma realidade independente da linguagem. Indo mais além, ao reconhecer o uso de uma infinidade de linguagens, percebeu sua vinculação a diversos interesses e intenções.

O fato de haver, em relação ao pensamento de Wittgenstein, uma divisão em duas fases indica que houve uma ruptura em seu pensamento. O próprio filósofo reconhece isto e chegou a dizer que, embora tivesse tentado corrigir a direção que, erradamente, indicou aos que o seguiram, não foi bem-sucedido ${ }^{4}$. Porém os estudiosos de seu pensamento, mesmo reconhecendo a ruptura ou reviravolta, não simplificam a questão. $\mathrm{Na}$ verdade, o que salta aos olhos são as diferenças e as críticas claras das idéias centrais elaboradas pelo primeiro Wittgenstein. A própria reflexão do segundo, porém, sugere não apenas que existem traços de continuidade, mas também que estes traços envolvem aspectos fundamentais do seu pensamento (Wrigley, 2002). De qualquer modo, a reflexão sobre a linguagem sempre foi central em sua reflexão filosófica. Conforme nos diz Coutinho $(1988)^{5}$, a grosso modo, o objetivo de Wittgenstein pode ser identificado com a tarefa atribuída por ele à filosofia, ou seja, a ordenação do nosso conhecimento sobre o uso da linguagem para que pudéssemos definir, assim, o que poderia ser dito sobre o mundo.

\section{ENTRELAÇANDO INQUIETAÇŌES ÉTICAS E FILOSÓFICAS}

Primeiramente, tendo em vista o momento histórico da elaboração do pensamento de Benjamin e Wittgenstein, faz sentido admitir que o interesse dos dois 
por uma "filosofia de linguagem" estaria, de certo modo, dado pelo horizonte de sua época, na qual os estudos sobre a linguagem receberam uma notável atenção. Contudo, o fato de terem desenvolvido caminhos tão diferentes era a pergunta que se colocava para nós como o desafio a ser enfrentado. Não era só uma questão de terem se dedicado a pensar aspectos conceituais diferentes, tendo a linguagem como referência, mas a diferença fundamental diz respeito ao próprio entendimento sobre as possibilidades de expandir os limites da linguagem e o resultado desta tentativa nas formas de viver e pensar. Tomamos como premissa o fato de que, a partir de um certo momento, o conhecimento de uma teoria colocada em diálogo com a outra permitiria avançar em uma compreensão da linguagem e da ética a partir de afinidades fundamentais. Podemos mencionar, por exemplo, o

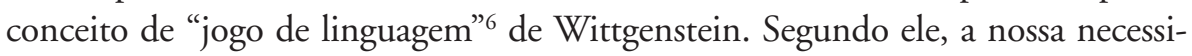
dade de generalização funciona como um obstáculo para investigarmos a variação que existe nas formas de linguagem, pois temos a tendência de procurar alguma coisa em comum a todas as coisas para classificá-las, usando um termo geral. Foi assim que, ao encontrar algumas expressōes no jogo de linguagem de Benjamin, a tarefa que se colocava era a de procurar alguma coisa em comum que autorizasse o diálogo com Wittgenstein. Em meio a estas questôes que ora se mostravam bem claramente, ora funcionavam como um pano de fundo das leituras, foram acontecendo descobertas surpreendentes, mas que ao mesmo tempo validavam o estranhamento quanto às muitas diferenças nas concepçôes de linguagem destes dois autores. O fundamental era não transformar este "algo" em comum em uma redução simplificada, o que apagaria a singularidade da reflexão complexa a que ambos se dedicaram. Muito pelo contrário, o essencial seria atingir a elaboração de um pensamento que justamente buscasse transitar em meio a tantas diferenças para fazer justiça à complexidade que uma reflexão teórica fecunda sobre a linguagem e a ética exige de nós.

Este caminho começou a ser apontado pela leitura de um artigo sobre Wittgenstein, "O lógico e a ética" de Margutti Pinto (2002), no qual o autor se propõe a falar sobre o papel da ética no pensamento do primeiro Wittgenstein, fazendo, contudo, uma ligação com as idéias do segundo. Faz, assim, uma análise da atmosfera intelectual, a qual classifica de peculiar, e que influenciou profundamente o jovem Wittgenstein. Separa essa atmosfera em três grupos: o primeiro, representado por James, Tolstói, Schopenhauer e Weininger, marcaria a tendência ético-metafísica que reconhece o misticismo como a experiência que dá sentido à vida. Tal experiência propõe uma revolução ética interior que implica a contemplação beatífica de uma realidade superior. O segundo grupo, composto por Hertz, Boltzmann, Frege e Russel, seria responsável pela tendência lógico-científica. Para 
eles, a análise lógica da linguagem resolveria a maioria dos problemas científicos e filosóficos, ou seja, acreditavam na capacidade da linguagem lógico-científica para descrever o mundo de maneira adequada. $\mathrm{O}$ terceiro grupo, composto somente por Mauthner, caracteriza-se por sua radicalização em direção à crítica da linguagem: defende um ceticismo extremo ao manifestar sua descrença na capacidade da linguagem para descrever a realidade, razão pela qual deveríamos parar de fazer perguntas e procurar respostas e nos refugiar no silêncio místico. Mauthner usou a imagem de uma escada que permitiria a crítica da linguagem, mas que, ao ser percorrida, só ofereceria uma solução: o suicídio da linguagem e a redenção no silêncio total.

Segundo Margutti Pinto (2002), há fortes indícios de que Wittgenstein acreditava no cristianismo tolstoiano, para o qual, na luta entre o espírito e a carne, a vitória seria conquistada na contemplação beatífica do eterno presente, via para encontrarmos o verdadeiro sentido da vida. Este cristianismo era colorido por uma influência schopenhaueriana, a qual faria corresponder o espirito ao sujeito transcendental, fora do espaço e do tempo, e a carne, ao sujeito individual ou empírico, constituído como um dos inúmeros fenômenos humanos.

Wittgenstein trabalhava com Frege e Russell e participava de suas crenças quanto à possibilidade da descrição científica do mundo por meio das técnicas de análise lógica. Mas isto entrava em choque com o ceticismo de Mauthner e fazia o filósofo viver um grande conflito. Talvez para tentar uma conciliação tenha optado por estabelecer, no interior da própria linguagem, o que poderia ou não ser dito. Diz Margutti Pinto (2002) que Wittgenstein ficou com um desafio ainda maior, ao tentar conciliar a análise lógica com o projeto ético.

Para Giron (2002), Wittgenstein almejou conciliar o idealismo transcendental schopenhauriano, característico da cultura alemã, com a filosofia de origem britânica:

No cérebro de Wittgenstein encontraram-se os dois hemisférios do planeta filosófico do século XIX - positivismo e idealismo -, que ele tentaria ultrapassar por meio de uma filosofia aforística, fragmentária e radical, próxima da nudez da poesia modernista. Se é que houve, a superaçấo da aporia que contrapunha realidade, idéia, lógica e linguagem se deu por meio de um corpo de pensamentos aparentemente estapafúrdio, que só ganha sentido se for solicitada a presença de uma entidade há muito fora de moda: a do gênio romântico (Giron, 2002: 47) .

Segundo Margutti Pinto (2002), Wittgenstein combinou duas escadas, no sentido mauthneriano, ao conciliar suas pesquisas lógicas com as convicções éticas, por meio de uma experiência peculiar de iniciação. 
Explicitada no Tractatus, a escada lógica reconheceu a linguagem como adequada à descrição de fatos. Haveria, assim, um paralelismo estrito entre a estrutura da linguagem e a do mundo, cuja essência seria representada pela ordem lógica das coisas. De outro modo, proposições sobre a essência abarcam condições tão gerais que ultrapassam o domínio dos fatos e não podem ser, assim, descritas pela linguagem.

Wittgenstein pôs a sua vida em risco várias vezes e viveu intensamente o sofrimento e os horrores da segunda guerra mundial. Sua escada ética possibilitou a experiência mística e, num de seus aforismos, declara que o místico existe e é inexprimível.

Margutti Pinto (2002) propõe que se compreenda a articulação entre as duas escadas como uma experiência de iniciação: a essência do mundo e da linguagem pode ser contemplada misticamente pelo sujeito transcendental, mas não pode ser colocada em palavras, ou seja, não pode "ser dita". Wittgenstein faz, então, a distinção entre dizer e mostrar: estando submetido às leis fenomênicas, o dizer é um fato mundano, enquanto que o mostrar pertence ao sujeito transcendental e ultrapassa estas mesmas leis. O Tractatus manifesta uma crítica da linguagem que tenta dizer o que apenas se mostra. Embora esta tentativa esteja fadada ao fracasso - e, entender assim as proposições do Tractatus, é percebê-las como contra-sensos -, ela gera a almejada clarificação conceitual, como se uma escada estivesse sendo percorrida:

Nesta, cada degrau é abandonado depois de percorrido porque envolve uma derrota parcial duma forma de dizer e uma vitória parcial duma forma de mostrar. Ao término do processo, a escada toda é abandonada como um grande contra-senso, porque reconhecemos finalmente a incapacidade da linguagem como um todo para exprimir o inexprimível. Em contrapartida, conseguimos subir por intermédio dela em direção a uma posição para além dela, que nos permite ver o mundo corretamente em silêncio (Margutti Pinto, 2002: 62).

Wittgenstein, no Tractatus, ao fazer a crítica da linguagem, compondo sua escada lógica, questiona os fundamentos do dizer. Esta, no entanto, não resolve o problema sobre a descoberta do sentido da vida. Ela precisa ser acompanhada de uma postura ética condizente com o seu questionamento radical. Ao colocar sua vida em risco, alistando-se como voluntário no exército austríaco, ele mostra que é preciso fazer igualmente uma crítica no sentido da própria vida. Para Margutti Pinto (2002), esta foi a razão que levou Wittgenstein a dizer, na descrição que fez ao seu editor, que o Tractatus possuía duas partes: a do texto escrito e a outra, a 
mais importante, que não foi escrita. Pode-se dizer assim que, no Tratactus, ele procurou pelas condiçôes transcendentais de possibilidade da linguagem. Já o segundo Wittgenstein, em sua fase posterior, se dedicou a refletir sobre as condiçōes contingentes de uso das expressões lingüísticas em uma forma de vida. Esta reflexão o levou a constatar que proposições metafísicas são contra-sensos que decorrem da má compreensão do funcionamento da linguagem.

Para Margutti Pinto (2002), no entanto, apesar das diferenças entre as duas filosofias, elas estão unidas pelo mesmo espírito: nas duas, Wittgenstein aponta em direção à contemplação silenciosa do absoluto como solução do problema ético. Enquanto no Tractatus a mensagem a este respeito é explícita, nas Investigaçôes filosóficas (Wittgenstein, [1953] 1996), a referência é mais sutil. Para ele, o fato de Wittgenstein ter afirmado, no prefácio desta obra, que sua nova filosofia deve ser compreendida em contraste com a antiga sugere alguma ligação entre as idéias ético-religiosas do Tratactus e as das Investigaçôes, ainda que nesta o silêncio sobre o misticismo seja total. Este autor não aceita que a nova perspectiva wittgensteiniana em relação à linguagem não passe de um "jogo de desconstrução" da filosofia tradicional, sem qualquer finalidade mais elevada. Dada a marca profunda deixada pela experiência mística na vida de Wittgenstein e as indicações preciosas em outros textos que escreveu, para este autor a visão ético-religiosa permaneceu uma questão viva, cuja prática da auto-renúncia para atingir a contemplação silenciosa do sentido da vida constituiria o ponto de ligação que dá continuidade a seu pensamento.

\section{Pensar Wittgenstein a partir de Benjamin e vice-versa}

Pensar a filosofia de linguagem de Wittgenstein a partir de provocações trazidas pela teoria de linguagem de Benjamin tem sido uma experiência instigante. Dentre muitas outras coisas, vale destacar a tomada de consciência quanto à complexidade do pensamento subjetivo reflexivo e seu processo de formação. Neste sentido, a obra Passagens, de Walter Benjamin ([1927-1940] 2006) ${ }^{7}$, nos oferece um vasto campo de reflexão para o enfrentamento das questóes sobre a teoria do conhecimento e o lugar ocupado pela linguagem e a ética neste campo, tendo como base textos fragmentários que nos fornecem pistas de pensamento, sem a pretensão de alcançarmos conclusões definitivas. $\mathrm{O}$ tema do conhecimento, atravessado pela linguagem e pela ética, se oferece como um campo permanente de indagaçôes que deve, a partir das leituras que fazemos das obras de Benjamin e Wittgenstein, permanecer nos interpelando ao longo de toda uma vida. É neste sentido que destacamos alguns fragmentos das obras de ambos, que soam como 
tentativas para encontrar soluções para a questão da escrita do texto filosófico, mas, sobretudo, explicitar através da escrita a articulação entre forma e conteúdo do pensamento, quando este pretende dar conta da experiência singular e expressar modos de vida e formas de pensar.

Método deste trabalho: montagem literária. Não tenho nada a dizer. Somente a mostrar. Não surrupiarei coisas valiosas, nem me apropriarei de formulaçōes espirituosas. Porém, os farrapos, os resíduos: não quero inventariá-los e sim fazer-lhes justiça da única maneira possível: utilizando-os (Benjamin, [19271940] 2006: 502).

Quando você está filosofando, deve descer ao caos primitivo e se sentir à vontade nele (Wittgenstein, [1929-1951] 1984: 65; tradução nossa).

Dizer algo sobre o próprio método da composição: como tudo em que estamos pensando durante um trabalho no qual estamos imersos deve ser-lhes incorporado a qualquer preço. Seja pelo fato de que sua intensidade aí se manifesta, seja porque os pensamentos de antemão carregam consigo um télos em relação a esse trabalho. É o caso também deste projeto, que deve caracterizar e preservar os intervalos da reflexão, os espaços entre as partes mais essenciais deste trabalho, voltadas com máxima intensidade para fora (Benjamin, [19271940] 2006: 499).

Ter sempre em mente que o comentário de uma realidade (pois trata-se aqui de um comentário, de uma interpretação de seus pormenores) exige um método totalmente diferente daquele requerido para um texto. No primeiro, a ciência fundamental é a teologia, no segundo a filologia (Benjamin, [19271940] 2006: 502).

Você poderia colocar preços nos pensamentos. Alguns custam muito e outros, pouco. E como alguém poderia pagar pelos pensamentos? A resposta, eu acho, é: com coragem (Wittgenstein, [1929-1951] 1984: 52; tradução nossa).

Uma palavra nova é como uma semente fresca fixada no solo da discussão. (Wittgenstein, [1929-1951] 1984: 2; tradução nossa)

Tornar cultiváveis regiōes onde até agora viceja apenas a loucura. Avançar com o machado afiado da razão, sem olhar nem para a direita nem para a esquerda, para não sucumbir ao horror que acena das profundezas da selva. Todo solo deve alguma vez ter sido revolvido pela razão, carpido do matagal do desvario e do mito. É o que deve ser realizado aqui para o solo do século XIX (Benjamin, [1927-1940] 2006: 499).

Eu me oponho à idéia de qualquer ideal de exatidão dado a priori. Em diferentes momentos nós temos diferentes ideais de exatidão e nenhum deles é supremo (Wittgenstein, [1929-1951] 1984: 37; tradução nossa). 
Um método científico se distingue pelo fato de, ao encontrar novos objetos, desenvolver novos métodos - exatamente como a forma na arte que, ao conduzir a novos conteúdos, desenvolve novas formas. Apenas exteriormente uma obra de arte tem uma e somente uma forma, e um tratado científico tem um e somente um método (Benjamin, [1927-1940] 2006: 515).

Ser dialético significa ter o vento da história nas velas. As velas são os conceitos. Porém não basta dispor as velas. O decisivo é a arte de posicioná-las (Benjamin, [1927-1940] 2006: 515).

Se o branco se transforma em preto algumas pessoas dizem: "essencialmente ainda é igual”. E outras, se a cor fica um tom mais escuro, dizem: mudou completamente (Wittgenstein, [1929-1951] 1984: 42; tradução nossa).

A redação deste texto que trata das passagens parisienses foi iniciada ao ar livre, sob um céu azul sem nuvens, arcado como uma abóbada sobre a folhagem e que, no entanto, foi coberto com o pó dos séculos por milhōes de folhas, nas quais rumorejam a brisa fresca do labor, a respiração ofegante do estudioso, o ímpeto do zelo juvenil e o leve e lento sopro da curiosidade. Pois o céu de verão pintado nas arcadas, que se debruça sobre a sala de leitura da Biblioteca Nacional de Paris, estendeu sobre ela seu manto opaco e sonhador (Benjamin, [19271940] 2006: 500).

Ao percorrer algumas das inquietações presentes no pensamento de Wittgenstein e Benjamin é possível perceber um pano de fundo comum para a reflexão destes dois pensadores, a influência do romantismo na obra de ambos. Segundo Lalande (1999), dá-se o nome de romantismo filosófico ou filosofia romântica à doutrina de um certo número de filósofos alemães do fim do século XVIII e dos primeiros anos do século XIX, que se caracterizava por uma reação contra o espírito e os métodos do século XVIII, pela desconfiança e depreciação das regras estéticas ou lógicas, pela apologia da paixão, da intuição, da liberdade, da espontaneidade, pela importância que atribuem à idéia de vida.

Para Abbagnano (1970), no romantismo houve a tentativa de ultrapassar os limites que o Iluminismo havia reconhecido como próprios da razão humana, pela vinculação à experiência mística e à fé. Assim, o que escapa à razão pode ser apreendido na fé, entendida como fato de sentimento ou de experiência imediata.

No caso de Benjamin, esta influência é mais explícita e, mesmo assim, não é com facilidade que os conhecedores e estudiosos de seu pensamento se apropriam de suas contribuições.

Podemos também dizer que o que Benjamin herdou da tradição do Iluminismo o orientou para a realização de uma teoria crítica da história, no seu caso, numa perspectiva marxista. Ele, porém, tentou conciliar este seu projeto 
com um sentimento místico ou, melhor dizendo, teológico. Segundo Calasso (1997), Benjamin revelou, "num raro e maravilhoso momento de confissão", em uma carta a Max Rychner, que nunca tinha podido pensar e estudar a não ser em um sentido teológico. Quanto à filosofia, Benjamin, ao concebê-la como uma experiência na linguagem, também a via como uma experiência religiosa, segundo Muricy (1999).

Caso queiramos comparar as soluçôes encontradas por Wittgenstein, em suas reflexões sobre a linguagem, com as de Benjamin, podemos dizer que este permaneceu na tarefa de dizer o indizivel. Ao tentar descrever na linguagem seu conceito de experiência, põe-nos em contato com algo que, em sua grandeza, sempre escapa, mas que ele nunca deixou de buscar. No ensaio "Sobre a linguagem em geral e sobre a linguagem humana", é Benjamin quem diz: "No seio de toda a concepção lingüística prevalece o conflito entre o expresso e o exprimível e o não expresso e o não exprimível” (Benjamin, [1916] 1992: 184).

No começo do ensaio, Benjamin concebe como uma "espécie linguagem" todas as manifestaçôes da vida intelectual do homem e isso parece ser o reconhecimento de uma (quase?) não distinção entre pensamento e linguagem, ou seja, uma ruptura com a visão representacional de linguagem:

De fato, é uma evidência plena de conteúdo a afirmação de que nada podemos imaginar que não comunique a sua essência espiritual, manifestando-a através da expressão; o maior ou menor grau de consciência a que tal processo de comunicação está ligado aparentemente (ou realmente) em nada altera o facto de sermos incapazes de imaginar a total ausência da linguagem, no que quer que seja. Uma existência que não tivesse relação com a linguagem é uma idéia; mas esta não frutifica, mesmo no domínio das idéias cujo âmbito é assinalado pela idéia de Deus.

Só pode afirmar-se que, nesta terminologia, qualquer expressão, desde que seja comunicação de um conteúdo intelectual, é considerada linguagem (Benjamin, [1916] 1992: 178).

Benjamin estende a existência da linguagem não só pelos domínios da manifestação intelectual do homem, mas, também, a todo o resto. Para ele, seja na natureza animada ou inanimada, todo acontecimento ou coisa participa na linguagem e, a todos, é essencial a comunicação do seu conteúdo espiritual. Apesar disso, Benjamin faz uma distinção entre essência lingüística e essência espiritual, quando diz que, para compreender uma essência lingüística, precisamos nos interrogar sobre qual a essência espiritual de que ela é a expressão imediata: 
A essência espiritual comunica-se na língua e não através dela, ou seja, de fora não é idêntica à essência lingüística. A essência espiritual é idêntica à lingüística só na medida em que é comunicável. A linguagem comunica, pois, a respectiva essência lingüística das coisas, mas a sua essência espiritual só a comunica na medida em que esta seja imediatamente contida na essência lingüística, na medida em que é comunicável. [...] Como se disse, não é o comunicável numa essência espiritual que aparece mais claramente na sua linguagem, mas sim este comunicável que constitui, imediatamente, a própria linguagem. O que numa essência espiritual é comunicável transmite-se nela, isto é, cada linguagem se comunica a si mesma (Benjamin, [1916] 1992: 179-180).

Nesta citação, Benjamin vê a linguagem como o medium da comunicação, na medida em que ela manifesta a expressão imediata do que nela se transmite. Para ele, este imediatismo é o problema fundamental da teoria da linguagem e até o vê como mágico, ao relacioná-lo com a linguagem em sua origem.

Novamente aí aparece a dimensão religiosa da reflexão do autor quando, apesar de dizer que a essência espiritual é comunicada na língua e não por meio dela, isso só acontece quando esta essência espiritual é comunicável. Podemos inferir que, para o autor, algo permanece na esfera do incomunicável... É que Benjamin (citando Hamann) tem a compreensão de que, na origem, a língua era tão natural, simples e próxima que poderia ser comparada a uma brincadeira de crianças. Esta condição, no entanto, se perdeu "logo que o homem saiu da situação paradisíaca em que só conhecia uma linguagem”. E continua: "a linguagem paradisíaca do homem deve ter sido a linguagem totalmente cognoscível" (Benjamin, [1916] 1992: 191). Poderíamos pensar, então, que o que era natural, estando irremediavelmente perdido, demandaria ao homem todo o esforço que o guiaria na tentativa de recuperar a "essência espiritual" na comunicação da experiência humana. Esta seria, assim, "manifestada na linguagem mesma, em sua expressão imediata, ou mágica”, como nos diz Muricy (1999). Para Benjamin, esta era a tarefa, por excelência, da filosofia que, com o seu envolvimento com a apresentação da verdade, encontra na linguagem esta possibilidade.

Ao perceber a força do pensamento de Benjamin em relação à sua crença na linguagem como uma possibilidade "mágica" de traduzir a experiência, o que se evidencia é a rejeição a uma visão de linguagem que a concebesse como mera possibilidade de comunicação. O que ele chama de mágica é esta função que a linguagem exerce de comunicar de forma imediata uma experiência. Benjamin concebe este "poder" como uma tentativa de reprodução, por substituição, de 
acontecimentos que se deram na origem da história do homem e que eram apreendidos diferentemente, de forma quase instantânea. No texto "Teoria das semelhanças", considera esta percepção "como de importância fundamental para a compreensão de grandes setores do saber oculto" (Benjamin, [1933] 1992: 59).

É muito interessante notar a peculiaridade da elaboração de Benjamin na sua visão de linguagem e, por tudo que foi visto até aqui, fica muito evidente a dimensão mística de seu pensamento. No entanto, ao pensarmos em sua obra, vemos que manifestava suas idéias com a intenção de mostrar uma forma de viver ligada à reflexão e à crítica, ou seja, uma forma política de estar na vida. Neste sentido, podemos dizer que, também Benjamin, assim como Wittgenstein, tinha uma concepção de linguagem como forma de vida.

Segundo Muricy (1999), Benjamin, em uma carta a um editor, manifesta sua desaprovação quanto ao equívoco de separar palavra e ação, porque, em se tratando desta questão, o ato é a linguagem em exercício e não algo que se acha no fim do processo. A linguagem, assim, seria retirada da condição de instrumento para objetivos nobres, porém exteriores a ela, como a ética ou a política: "ela é um fim em si, por si só um ato” (Benjamin, citado por Muricy, 1999: 89).

No pensamento de Benjamin, o que causa estranhamento e parece ambigüidade é que, para ele, o fato de pensar numa forma política de estar na vida está ligado a uma compreensão que se baseia numa profunda religiosidade. Como já vimos, em sua visão todas as coisas existentes têm uma linguagem, no sentido de possuírem uma essência espiritual: "a comunicação das coisas é, certamente, de um tipo de comunidade, que considera o mundo, em geral, como um todo indivisível" (Benjamin, [1916] 1992: 195). Porém é a linguagem humana que expressa essa essência, ao retirar as coisas de sua mudez. $\mathrm{O}$ homem foi elevado acima da natureza por meio da língua, como uma dádiva de Deus: "Deus não criou o homem a partir da palavra, e não o denominou. Não quis subordiná-lo à língua, mas sim libertar de si no homem a língua que the tinha servido como medium de criação: Deus descansou quando abandonou a si mesma no homem a sua força criadora" (Benjamin, [1916] 1992: 187).

Podemos pensar que Benjamim, ao acreditar na potência de uma ação política transformadora do homem, na história, conceberia a linguagem como manifestação desta experiência, como uma forma de vida que estaria fazendo justiça ao seu dom de criação concedido por Deus.

A dimensão espiritual do seu pensamento o fez entender que a linguagem "não é apenas comunicação do que é comunicável, mas, simultaneamente, símbolo do não-comunicável” (Benjamin, [1916] 1992: 196). 
Benjamin, em sua obra, parece ter se comprometido com a possibilidade de comunicar o incomunicável e sua tentativa é muito inspiradora quanto a possíveis escolhas que façamos em relação a formas de pensar e de viver.

Para o primeiro Wittgenstein, esta tendência humana é nobre, e toda a tentativa de alargar os muros da linguagem é ética, apesar de não haver esperança quanto a essa possibilidade. Como para ele, nessa fase, o pensamento representaria somente fatos, os mais profundos e importantes problemas da vida pertenciam ao terreno obscuro do que poderíamos chamar de místico. Mas, segundo Edwards (1982), Wittgenstein não exclui os problemas de conduta da alçada da ética com a sua filosofia. Considera, porém, que o verdadeiro centro do interesse ético está em outro lugar. Na verdade, as questôes éticas se equiparam às consideraçôes usualmente tidas como religiosas: "ambas, religião e ética, têm a ver com o sentido do mundo e da vida, um sentido sem o qual a existência humana seria insuportável" (Edwards, 1982: 32).

Constatamos que Benjamin, em 1913, no texto O ensino da moral, já apresentava as mesmas inquietaçōes de Wittgenstein, quando, ao analisar o tema da ética e da religião, afirmou: "Enquanto hoje em dia multiplicam-se por toda a parte as vozes que consideram eticidade e religião como esferas fundamentalmente independentes, a nós parece que apenas na religião, e tão somente na religião, a vontade pura encontra o seu conteúdo. O cotidiano de uma comunidade ética é plasmado de maneira religiosa" (Benjamin, [1913] 2002: 15).

Mais adiante, neste mesmo texto, Benjamin acrescenta:

A lei ética não se deixa apreender com maior exatidão pelos meios do intelecto, isto é, de maneira universalmente válida. Pois onde e como a lei ética recebe os seus conteúdos concretos, isso é determinado pela religiosidade do indivíduo particular. E ultrapassar as barreiras aqui estabelecidas ou penetrar na relação ainda indefinida entre indivíduo particular e eticidade, tal coisa é vedada pelas palavras de Goethe: "O mais elevado no homem é amorfo e deve-se evitar plasmá-lo senão mediante uma ação nobre”. Quem se permite hoje em dia (fora da Igreja) a desempenhar o papel de mediador entre homem e Deus? Ou quem vai querer introduzir esse papel de mediador na educação, uma vez que se espera que toda a eticidade e religiosidade emanem de estar a sós com Deus? (Benjamin, [1913] 2002: 15-16).

Por sua vez, Wittgenstein, em uma conferência sobre ética, depois de dez anos afastado da filosofia, explica à sua audiência: 
Suponha que um dentre vocês seja onisciente, e que por conseqüência tenha conhecimento de todos os corpos, mortos ou vivos, deste mundo. Que conheça igualmente todas as disposições do espírito de todos os seres humanos em qualquer época que eles tenham vivido, e que tenha escrito tudo que conhece dentro de um grosso livro; este livro conteria a descrição completa do mundo. E o ponto a que eu quero chegar é que este livro não conteria nada que nós chamaríamos de um julgamento ético nem o que quer que seja que implicaria logicamente um tal julgamento. [...] Me parece evidente que nada do que nós pudéssemos jamais pensar ou dizer poderia ser esta coisa, a ética; que nós não poderíamos escrever um livro científico que tratasse de um assunto sublime e de um nível superior a todos os outros assuntos. Eu só poderia descrever meu sentimento a este propósito por esta metáfora: se um homem pudesse escrever um livro sobre a ética, que fosse realmente um livro sobre ética, este livro, como uma explosão, aniquilaria todos os outros livros deste mundo. [...] A ética, se ela existe, é sobrenatural, enquanto que nossas palavras só querem exprimir fatos (Wittgenstein, [1929] 1992: 145-147; tradução nossa).

Para sermos coerentes com a filosofia do segundo Wittgenstein, não poderíamos pensar na ética como algo fora do que conseguiríamos pensar ou dizer, porém ele mesmo permaneceu em silêncio sobre isso. De fato, na medida em que na segunda fase de sua reflexão filosófica o pensamento e a linguagem são desmistificados, a ética também perde seu ar de mistério: já não há mais restrições filosóficas sobre o que pode ser dito sobre o seu conteúdo. O silêncio de Wittgenstein se mantém, no entanto, como uma evitação ao impulso metafísico. Para ele, tal impulso passa a ser visto como um sintoma de um mal entendimento que precisa ser "curado". Tenta impedir, assim, que a sua sensibilidade ética possa parecer uma nova tese filosófica. Sua visão ética deve, portanto, estar escondida: mostrada, sem ser dita. Na verdade, na sua filosofia tardia, Wittgenstein passou a rejeitar a prática da teorização que era característica da filosofia tradicional e, nesse contexto, dedicou-se a exercer uma crítica rigorosa contra a aproximação da filosofia com o modelo científico.

Mais cedo, na conferência de $1929^{8}$, o filósofo dá exemplos de experiências que mostram do que, para ele, se ocupa a ética e, com isso, parece querer provocar em seu auditório a lembrança de experiências similares. Não há garantia de que a audiência tenha vivido tais experiências, porém, com os exemplos, Wittgenstein busca um meio de se exprimir, de comunicar um "modo de ver" em relação à ética, que conta com o envolvimento das pessoas por conta de suas próprias experiências na vida. 
É importante mencionar que em anotações de uma conversa que teve com Schlick Wittgenstein se refere à conferência para relembrar que, em seu final, ele fala na primeira pessoa e que isso aponta para algo essencial, qual seja, para o fato de que só pode entrar em cena como uma pessoa e dizer "eu", pois uma teoria não teria valor, "não lhe daria nada" (Wittgenstein, [1929] 1992: 158). Nesse sentido, Wittgenstein se esforçou para arranjar um meio de descrição compatível com o conteúdo que queria comunicar. Assim, com seu relato de experiências, ele se mostra longe da idéia de que uma concepção moral deve estar sistematicamente pronta para a argumentação ou para ser submetida a uma crítica racional, ao modo da ciência.

O jovem Walter Benjamin, aos 22 anos, acreditava na possibilidade de a juventude agir e, deste modo, mostrar como perseverar e encontrar alternativas para as questôes da vida que realmente importam. Para ele, o jovem, na sua condição de querer experimentar o mundo de um modo outro, estaria na posição de comandar verdadeiras transformaçôes, inovar ao agir no mundo e ser fiel às suas conviç̧ôes. Em um texto de 1914 (2002), "O posicionamento religioso da nova juventude”, Benjamin explicita a sua profunda compreensão da religião e da ética no contexto da ação política e mostra que o jovem tem urgência de exercitar a liberdade de escolha, ou seja, experimentar o mundo de um modo singular.

Não há nada que a juventude exija com mais urgência do que a escolha, a possibilidade da escolha, da decisão sagrada sobretudo. A escolha gera seus próprios objetos - esta é a sua convicção mais próxima da religião.

A juventude que faz profissão de fé de si mesma significa uma religião que ainda não existe. Cercada pelo caos de coisas e homens, dos quais nenhum é sagrado, nenhum condenado, ela clama pela escolha. E antes que a graça crie novamente o sagrado e o profano ela não poderá escolher com a mais profunda seriedade. Ela confia em que o sagrado e o réprobo se revelarão no momento em que a vontade comum de escolha tiver alcançado a máxima tensão (Benjamin, [1914] 2002: 28-29).

É muito interessante notar que Wittgenstein e Benjamin, em suas reflexōes sobre a linguagem, enfrentaram problemas parecidos, aos quais, porém, pelas circunstâncias da vida de cada um, deram respostas totalmente relacionadas aos conteúdos de suas experiências singulares. No entanto, o compromisso que os dois mostram em seus trabalhos com o rigor na construção de conhecimento não se separa de um modo de ver e viver a vida.

Vimos que o primeiro Wittgenstein acreditava na possibilidade da descrição científica do mundo por meio das técnicas de análise lógica, ainda que essa descri- 
ção deixasse de fora, justamente, proposições sobre a ética, um tema humano de grande importância. Já em sua filosofia tardia, Wittgenstein se dedicou a refletir sobre as condições contingentes de uso das expressões lingüísticas em uma forma de vida. Esta reflexão o levou a constatar que proposições metafísicas são contrasensos que decorrem da má compreensão do funcionamento da linguagem. Dentro dessa perspectiva, tampouco encontramos na filosofia do segundo Wittgenstein uma teoria sobre a ética, já que para ele este termo "ética" é empregado em sistemas de pensamento variados e, portanto, não existiria um só sistema a partir do qual pudéssemos estudar a ética em sua essência ou pureza. $\mathrm{Na}$ verdade, para o segundo Wittgenstein, a ética se mostraria no campo da vida por meio das ações humanas, bem como na tarefa de explicitar as razões para os nossos atos, nossas decisóes e escolhas. O filósofo, no seu esforço para desconstruir verdades estabelecidas pela tradição filosófica, traz a discussão da ética para o campo das práticas sociais. Nesse sentido, reconhece que no contexto das decisões éticas há influências da educação, persuasão, acordos etc. Indo mais além, sua reflexão nos faz ver que uma certa constância na proclamação de alguns valores entre os falantes de uma comunidade lingüística nos dão condições de confrontar os discursos com o que vemos acontecer nas práticas.

A qualidade da filosofia de Wittgenstein o fazia desconfiar profundamente do progresso científico: para ele, a solução para as questôes concernentes à ética implicava uma mudança no modo de vida das pessoas, ou seja, uma solução existencial, ao invés de teórica. Sob esse aspecto, a segunda fase do seu pensamento pode ser entendida como uma aproximação maior da reflexão intelectual em relação à coerência de ações práticas na vida. Assim, quando Wittgenstein abandona a idéia de investigar a lógica formal e passa a investigar a lógica contida na linguagem ordinária, nos dá uma pista do que, para ele, verdadeiramente, importava e precisava ser esmiuçado.

Benjamin, desde o início, se insurgiu contra a ótica de uma perspectiva utilitarista em relação à linguagem. Pelo contrário, como vimos, ele atribui a ela um caráter sagrado, mágico. Nesse sentido, encontramos nele uma reflexão profunda no que diz respeito à função e ao uso da linguagem no mundo e uma intuição especial quanto à sua natureza. $\mathrm{Na}$ verdade, a concepção de linguagem benjaminiana, estando ligada ao conceito de experiência, expressa uma espécie de denúncia quanto ao perigo da alienação a que está sujeito o homem no mundo contemporâneo. Aqui, a reflexão de Benjamin se aproxima à de Wittgenstein, ao chamar a atenção para a separação que existe entre o discurso proferido e as práticas que revelam nossas crenças mais profundas quanto ao que acreditamos que é possível construir. Nesse sentido, o filósofo nos convida ao desafio de escapar ao 
maquinismo infernal de uma linguagem que submete o homem à servidão de pensamento e, conseqüentemente, à repetição cega de práticas sem sentido (Jobim e Souza, 2008). Como nos diz Muricy (2008), para Benjamin "construir idéias é recuperar \% na linguagem domesticada pelo uso pragmático das exigências de informação e comunicação \% uma dimensão inaudita, onde possa brotar algo como uma origem sempre renovável" (Muricy, 2008: 79).

A qualidade da reflexão dos dois autores não permite conclusões definitivas e as fronteiras que demarcam suas diferenças e semelhanças flutuam constantemente para exercer o seu papel. De todo modo, a integridade de suas contribuições é, sem dúvida, muito inspiradora quanto a possíveis escolhas que façamos em relação a formas de pensar e de viver.

\section{REFERÊNCIAS BIBLIOGRÁFICAS}

Abbagnano, N. (1970). Dicionário da filosofia. São Paulo: Mestre Jou.

Albuquerque, E. D. P. A. (1998). Linguagem e produção de conhecimento: uma chave de leitura para as relaçôes intersubjetivas no contexto escolar. Dissertação de mestrado, Departamento de Psicologia, Pontifícia Universidade Católica do Rio de Janeiro.

Benjamin, W. (1913/2002). O ensino da moral. In: Reflexōes sobre a criança, o brinquedo e a educação. São Paulo: Editora 34.

- (1914/2002). O posicionamento religioso da nova juventude. In Reflexões sobre a criança, o brinquedo e a educação. São Paulo: Editora 34.

. (1916/1992). Sobre a linguagem em geral e sobre a linguagem humana. In Sobre arte, técnica, linguagem e política. Lisboa: Relógio d'Água. . (1927-1940/2006). Passagens. Belo Horizonte: Editora da UFMG.

. (1933/1992). Teoria das semelhanças. In Sobre arte, técnica, linguagem e politica. Lisboa: Relógio d'Água.

Calasso, R. (1997). Os 49 degraus. São Paulo: Companhia das Letras.

Coutinho, A. R. (1988). On language and sensations: Wittgenstein on the language of inner experience (mimeogr.).

- (1996a). Cientificidade e relevância social - Parte I: controvérsias sobre cientificidade da psicologia e das ciências sociais. Psicologia: teoria e pesquisa, 12, 1, 23-37.

- (1996b). Cientificidade e relevância social - Parte II: uma discussão da questão da cientificidade e suas implicaçôes sociais. Psicologia: teoria e pesquisa, 12, 2, 165-177. Edwards, J. C. (1982). Ethics without philosophy: Wittgenstein and the moral life. Florida: University Presses of Florida. 
Giron, L. A. (2002). Uma mente em chamas. In: Revista Cult (pp. 46-50). São Paulo: Editora 17.

Jobim e Souza, S. (2008). Walter Benjamin e a infância da linguagem In: Revista Educação, março (pp. 36-47). São Paulo: Editora Segmento.

Lalande, A. (1999). Vocabulário técnico-crítico da filosofia, v. II. São Paulo: Martins Fontes.

Lampreia, C. (2002). O percurso de uma vida dedicada ao conhecimento. Psicologia clínica, 14, 2, 123-134.

Marcondes, D. (2004). Filosofia analítica. Rio de Janeiro: Jorge Zahar.

Margutti Pinto, P. R. (2002). O lógico e a ética. In: Revista Cult, agosto (pp. 60-63). São Paulo: Editora 17.

Muricy, K. (1999). Alegorias da dialética. Rio de Janeiro: Relume Dumará.

. (2008). A magia da linguagem \% filosofia, linguagem e escrita em Walter Benjamin. In: Revista Educação, março (pp. 76-85). São Paulo: Editora Segmento.

Urdánoz, T. (1984). Historia de la filosofía, VII. Madrid: Biblioteca de Autores Cristianos. Wittgenstein, L. (1921/1993). Tractatus logico-philosophicus. São Paulo: EDUSP.

- (1929/1992). Leçons et conversations sur l'esthétique, la psychologie et la croyance religieuse. Paris: Gallimard.

. (1929-1951/1984). Culture and value. Chicago: The University of Chicago Press. . (1953/1996). Investigações filosóficas. Petrópolis: Vozes.

Wrigley, M. (2002). A tarefa sem fim. In: Revista Cult, agosto (pp. 58-59). São Paulo: Editora 17.

\section{Notas}

1 Num sentindo amplo, a filosofia analítica se daria pelo emprego do método analítico para o tratamento das questôes filosóficas. Na história da filosofia, no entanto, a filosofia analítica é uma corrente que adota o método analítico e surge ao final do século XIX, desenvolvendo-se ao longo do século XX até os nossos dias, o que a caracteriza como uma das principais correntes do pensamento contemporâneo (Marcondes, 2004).

2 O idealismo subjetivista dominou, em grande parte, a filosofia do século XIX. Para maiores esclarecimentos, ver Albuquerque (1998).

3 Para Wittgenstein, proposição é uma imagem ou modelo da realidade.

4 As idéias de Wittgenstein influenciaram a corrente de pensamento do positivismo lógico.

5 A professora Anamaria Ribeiro Coutinho [1940-2002] encontrou no pensamento de Wittgenstein valiosas pistas para desenvolver suas próprias reflexões. No Departamento de Psicologia da PUC-Rio, ela foi responsável pela divulgação das idéias do filósofo. Em suas 
aulas, seus alunos tiveram a oportunidade inesquecível de partilhar seus interesses e, sobretudo, perceber o seu compromisso rigoroso com a construção do conhecimento, ao vê-la enfrentar os impasses que são próprios do caminho de quem pensa corajosa e dedicadamente. Ver o artigo de Carolina Lampreia (2002), "O percurso de uma vida dedicada ao conhecimento", Psicologia Clínica, v. 14. Ver também dois artigos de Coutinho (1996a, 1996b).

6 Como as palavras ou expressões não têm um só uso, essencial a elas, o significado vem dos sistemas concretos ou jogos de linguagem em que são empregadas. Wittgenstein introduz a idéia de jogo de linguagem, dizendo que eles são as formas de linguagem com as quais uma criança começa a falar. Para ele, estudá-las é estudar primitivas formas de linguagem e primitivas linguagens, o que traria a grande vantagem de se perceber que nelas estas formas de pensar aparecem sem o confuso pano de fundo de processos de pensamento mais elaborados e complicados. Assim, quando olhamos para estas simples formas de linguagem, nosso entendimento sobre o uso de nossa linguagem ordinária se transforma, na medida em que o que vemos são atividades, reações, que são claras e transparentes. Por outro lado, reconhecemos, nestes processos simples, formas de linguagem que não são separadas por uma ruptura de nossas formas de linguagem mais elaboradas: vemos que podemos construir formas mais complicadas a partir das mais primitivas, acrescentando, gradualmente, novas formas.

7 Esta obra foi traduzida para o português e lançada em 2006 pela Editora da UFMG, representando um importante acontecimento no que diz respeito aos estudos acadêmicos de Walter Benjamin no Brasil.

8 Esta conferência é considerada um trabalho de transição do pensamento da primeira para a segunda fase do pensamento de Wittgenstein.

Recebido em 17 de março de 2008 Aceito para publicação em 15 de maio de 2008 